Review

\title{
Nanotoxicity: An Interplay of Oxidative Stress, Inflammation and Cell Death
}

\author{
Puja Khanna, Cynthia Ong, Boon Huat Bay and Gyeong Hun Baeg * \\ Department of Anatomy, Yong Loo Lin School of Medicine, National University of Singapore, \\ 4 Medical Drive, MD10, Singapore 117 597, Singapore; E-Mails: puja_khanna@u.nus.edu (P.K.); \\ cynthiaong@u.nus.edu (C.O.); boon_huat_bay@nuhs.edu.sg (B.H.B.) \\ * Author to whom correspondence should be addressed; E-Mail: antbgh@nus.edu.sg; \\ Tel.: +65-165-9787-9301; Fax: +65-165-6778-7643.
}

Academic Editor: Robert Tanguay

Received: 15 May 2015 / Accepted: 23 June 2015 / Published: 30 June 2015

\begin{abstract}
Nanoparticles are emerging as a useful tool for a wide variety of biomedical, consumer and instrumental applications that include drug delivery systems, biosensors and environmental sensors. In particular, nanoparticles have been shown to offer greater specificity with enhanced bioavailability and less detrimental side effects as compared to the existing conventional therapies in nanomedicine. Hence, bionanotechnology has been receiving immense attention in recent years. However, despite the extensive use of nanoparticles today, there is still a limited understanding of nanoparticle-mediated toxicity. Both in vivo and in vitro studies have shown that nanoparticles are closely associated with toxicity by increasing intracellular reactive oxygen species (ROS) levels and/or the levels of pro-inflammatory mediators. The homeostatic redox state of the host becomes disrupted upon ROS induction by nanoparticles. Nanoparticles are also known to up-regulate the transcription of various pro-inflammatory genes, including tumor necrosis factor- $\alpha$ and IL (interleukins)-1, IL-6 and IL-8, by activating nuclear factor-kappa B (NF-кB) signaling. These sequential molecular and cellular events are known to cause oxidative stress, followed by severe cellular genotoxicity and then programmed cell death. However, the exact molecular mechanisms underlying nanotoxicity are not fully understood. This lack of knowledge is a significant impediment in the use of nanoparticles in vivo. In this review, we will provide an assessment of signaling pathways that are involved in the nanoparticleinduced oxidative stress and propose possible strategies to circumvent nanotoxicity.
\end{abstract}


Keywords: nanoparticles; nanotoxicity; ROS generation; oxidative stress; inflammation; DNA damage; apoptosis

\section{Introduction}

Nanotechnology encompasses the study and manipulation of particles at the nanoscale $(1-100 \mathrm{~nm})$ level, commonly known as nanoparticles [1]. Nanoparticles have unique mechanical and physicochemical properties due to their increased relative surface area and quantum effects, favoring their usage in various applications [2,3]. In the past decade, the field of nanotechnology has received considerable attention due to its wide variety of applications being extended to the biotechnology, electronics, aerospace and computer industry. More recently, nanotechnology is also applied to the field of nanomedicine, which covers nanotechnology-based diagnosis, treatment and prevention of human diseases such as cancer, improving human health and well-being [4].

Nanoparticles are frequently used as a tool for drug delivery in nanomedicine. They can be categorized into several different groups such as polymers, inorganic nanoparticles and metallic nanoparticles, depending on their physicochemical properties.

Polymers such as polysaccharide chitosan nanoparticles (CS-NPs) function in drug delivery due to their ability to facilitate both protein and drug conjugation [5]. The polymer-protein conjugates enhance protein stability but reduce immunogenicity, whereas the polymer-drug conjugates display enhanced permeability and retention effects [6]. More recently, the polymeric nanoparticle poly-(lactic-co-glycolic acid) (PLGA) has also been used as a nanocarrier for drug delivery across the blood-brain barrier due to its biocompatibility and biodegradability, thereby ensuring safe therapy [7]. Inorganic ceramic nanoparticles such as silica, titania and alumina are also commonly being used for drug administration for cancer therapy due to their porous nature, although their applications are limited due to their non-biodegradable nature [8,9]. On the other hand, metallic nanoparticles, including superparamagnetic iron oxide nanoparticles, gold shell nanoparticles and titanium dioxide $\left(\mathrm{TiO}_{2}\right)$ nanoparticles, are routinely used for magnetic resonance imaging contrast enhancement and as cancer drug carrier systems, whereas silver nanoparticles (AgNP) are being explored as antibacterial agents for treatment of infectious diseases, due to their ability to stabilize nanoparticles and favorable optical/chemical properties [10-15]. Notably, carbon nanoparticles, which are comprised of fullerenes and nanotubes, are the most widely used materials for drug delivery purposes due to the fact that fullerenes contain multiple attachment points responsible for tissue binding, and nanotubes offer high electrical conductivity and strength [16,17].

Nanoparticles have been used as a tool for the detection of disease biomarkers in both in vivo and ex vivo diagnostic applications, consequently leading to an advancement of proteomics and genomics technologies [18-20]. For example, streptadivin-coated fluorescent polystyrene nanospheres offer greater sensitivity in the detection of epidermal growth factor receptor (EGFR) in human carcinoma cells, thus providing a more sensitive tool for biomarker discovery [21]. Furthermore, an ultrasensitive nanoparticle-based assay for the detection of prostate-specific antigen (PSA) in the serum was developed, which can provide up to six orders of magnitude higher sensitivity than the conventional 
assay [22]. Therefore, nanoparticles have also gained popularity in the field of molecular diagnosis and imaging, due to their favorable physicochemical properties of small particle size, flexibility of surface coating and enhanced stability [23,24].

Nanotechnology has also found an application in molecular imaging, particularly in magnetic resonance imaging (MRI), fluorescence imaging, computed tomography imaging and ultrasound techniques [25-27]. Gadolinium-based paramagnetic nanoparticles targeting fibrin in atherosclerotic plaques allowed for more effective imaging as compared to the commonly used contrast agents; in turn promoting early detection of vulnerable plaques [28-30]. Moreover, nanoparticles have been shown to not only increase specificity of targeting but also increase/facilitate solubility, stability and absorption of the drug [31,32]. Particularly, nanoparticle formulations carrying anti-cancer drugs, including paclitaxel, 5-fluorouracil and doxorubicin, have been observed to be more efficient drug delivery systems, by enhancing the cytotoxic effects of the drug while reducing non-specific targeting of normal cells [33-35].

\section{Toxicity of Nanoparticles}

Despite the gaining popularity of nanotechnology in the field of medicine, their applications have been restricted due to their potential toxicity and long-term secondary adverse effects [2]. Nanotoxicology includes the study of the toxicity of nanomaterials to better understand and assess the health risks involved in the use of nanoparticles. The physicochemical properties of nanoparticles, such as small size, large surface area and flexible chemical composition/structure that favor their use in nanomedicine, have also been found to contribute to their enhanced toxicological side effects [36]. Specifically, particle size and surface area are considered important factors that contribute directly and significantly to toxicity of nanoparticles, with smaller sized nanoparticles exhibiting higher toxic effects due to increased surface area [37]. Apart from size, structure and shape of the nanoparticle also contribute to nanotoxicity. For example, studies with carbon nanofibers, single-wall nanotubes (SWCNTs) and multi-wall nanotubes (MWCNTs), have revealed that the toxicity of carbon material with high-aspect ratio is determined by particle form and dimensions [38]. Moreover, the nanoparticle surface dictates the adsorption of ions and biomolecules, thus influencing the cellular responses elicited, and thereby contributing to nanoparticle induced toxicity [39].

Humans can be exposed to nanomaterials via several routes such as inhalation, injection, oral ingestion and the dermal route. Specifically, the respiratory system, gastrointestinal tract, the circulatory system as well as the central nervous system are known to be adversely affected by nanoparticles [23]. In vivo experiments have revealed that carbon nanotubes are found to cause dose-dependent epithelioid granulomatous lesions in the lung and persistent interstitial inflammation on chronic exposure [40,41]. Furthermore, ceramic nanoparticles, commonly used for drug delivery, have been reported to exhibit oxidative stress/cytotoxic activity in the lungs, liver, heart, and brain, as well as have teratogenic/carcinogenic effects [42].

In addition to causing detrimental respiratory effects, nanoparticles administered via injection have been shown to enter the systemic circulation, causing secondary complications in the circulatory system and further gain access to the central nervous system. Engineered carbon nanoparticles and nanotubes were found to induce the aggregation of platelets in vitro, and thus enhance vascular 
thrombosis in rat carotid artery [43]. Furthermore, the effect of SWCNTs was studied in cellular models of human kidney and bronchi, where they were observed to induce cell apoptosis and decrease cell adhesion via either upregulating genes involved in cell death or downregulating genes associated with cell proliferation and survival [44,45]. Wistar rats injected intraperitoneally with $20 \mathrm{mg} / \mathrm{kg}$ titanium dioxide nanoparticles $\left(\mathrm{TiO}_{2} \mathrm{NPs}\right)$ every two days for 20 days, revealed an accumulation of $\mathrm{TiO}_{2} \mathrm{NPs}$ in the liver, lung and brain, and an increase in aspartate aminotransferase/alanine aminotransferase ratio (AST/ALT ratio), indicating subacute toxicity. In the injected rats, pathological changes were found in the liver and abnormal neuro-behavioural performance, as evidenced by the increased anxious index was observed, suggesting that $\mathrm{TiO}_{2} \mathrm{NPs}$ are able to translocate and biodistribute to various organs leading to toxicity effects [46].

Oral ingestion of a single dose of $500 \mathrm{mg} / \mathrm{kg}$ titanium dioxide $\left(\mathrm{TiO}_{2}\right)$, zinc oxide $(\mathrm{ZnO})$ and aluminium oxide $\left(\mathrm{Al}_{2} \mathrm{O}_{3}\right)$ nanoparticles, were shown to result in nanoparticle translocation to the central nervous system. These nanoparticles accumulated in the brain and caused axillary toxicity, disrupting normal metabolism of neurotransmitters and ultimately leading to brain damage [47]. The effect of different sized $\mathrm{TiO}_{2}$ nanoparticles were studied in rat astrocytes, in which these nanoparticles were found to inhibit cell survival rates in a dose-dependent manner, with pathological effects such as blood-brain barrier destruction, cellular oedema and brain tissue necrosis [48]. Furthermore, nano-manganese dioxide $\left(\mathrm{MnO}_{2}\right)$ was also found to cause dopaminergic neuronal dysfunction and astrocyte activation, thus affecting the learning abilities of rats [49].

Dermal exposure of nanoparticles is often mediated through the use of nanomaterial containing cosmetic products or wound dressings. For instance, sunscreens containing $\mathrm{TiO}_{2}$ were found to pass through the stratum corneum and in the deeper parts of hair follicles [50]. In addition, Acticoat, a nanocrystalline silver-coated wound dressing, is now being used for treatment in burn patients. Despite various studies reporting about the safety of Acticoat for the use on burn patients, silver toxicity was reported in a patient with 30\% burns who had received the silver-coated dressing for treatment [51].

The accumulation of nanoparticles in various organs and adverse side effects have hindered their use in the field of nanomedicine, and have deterred full exploitation of their potential in molecular diagnostics and as drug delivery systems (Table 1). A better understanding of the mechanisms involved in nanotoxicity may provide clues for circumventing the toxicological effects of nanoparticles and may help to further develop/exploit nanoparticles in the field of nanomedicine.

Table 1. Overview of the different types of nanoparticles used in nanomedicine, and the toxicity associated.

\begin{tabular}{ccc}
\hline Class/Type of Nanoparticles & Application in Nanomedicine & Toxicity \\
\hline Polymeric nanoparticles & Drug delivery [5] & Not reported \\
\hline $\begin{array}{c}\text { Polysaccharide chitosan } \\
\text { nanoparticles (CS-NPs) }\end{array}$ & Cancer therapy and drug delivery [7] & Not reported \\
\hline $\begin{array}{c}\text { Poly-(lactic-co-glycolic acid) } \\
\text { (PLGA) }\end{array}$ & & \\
\hline Inorganic nanoparticles & & \\
\hline
\end{tabular}


Table 1. Cont.

\begin{tabular}{ccc}
\hline Class/Type of Nanoparticles & Application in Nanomedicine & Toxicity \\
Silica nanoparticles & Drug delivery/Diagnostic imaging [9] & $\begin{array}{c}\text { Platelet aggregation and } \\
\text { physiological toxicity [52], } \\
\text { reproductive toxicity [53] }\end{array}$ \\
\hline Ceramic nanoparticles & Cancer drug delivery [8] & $\begin{array}{c}\text { Oxidative stress/cytotoxic activity } \\
\text { in the lungs, liver, heart, and brain } \\
\text { [42] }\end{array}$ \\
\hline Metallic nanoparticles & Magnetic resonance imaging contrast \\
\hline $\begin{array}{c}\text { Superparamagnetic iron } \\
\text { oxide nanoparticles }\end{array}$ & enhancement, immunoassays and cancer drug \\
carrier systems [11,12] & $\begin{array}{c}\text { Oxidative stress and disturbance in } \\
\text { iron homeostasis [54] }\end{array}$ \\
\hline Gold shell nanoparticles & Biomedical imaging and therapeutics [13] & Hepatic and splenic toxicity [55] \\
\hline Titanium dioxide & Cancer therapeutics [14] & $\begin{array}{c}\text { Toxicity to the central nervous } \\
\text { system [46,47] }\end{array}$ \\
\hline Silver nanoparticles & Antibacterial agents [15] & $\begin{array}{c}\text { ER stress response not only in the } \\
\text { lung, liver and kidneys [56] }\end{array}$ \\
\hline $\begin{array}{c}\text { Carbon nanoparticles } \\
\text { (fullerenes and nanotubes) }\end{array}$ & Drug delivery [16,17] & $\begin{array}{c}\text { Pulmonary toxicity and interstitial } \\
\text { inflammation [40,41] }\end{array}$ \\
\hline
\end{tabular}

\section{Molecular Mechanisms Underlying Nanotoxicity}

\subsection{Oxidative Stress and DNA Damage}

Nanoparticles are known to induce reactive oxygen species (ROS) production, leading to an oxidative stress when redox state of the cell is imbalanced [57-60]. ROS induction by nanoparticles is considered the primary cause of nanotoxicity, and has been attributed to the presence of pro-oxidant functional groups on their reactive surface or due to nanoparticle-cell interactions [61,62]. ROS production is a normal cellular process which is involved in varied aspects of cellular signaling, as well as in the defence mechanism of the immune system. However, in excess it has been found to cause severe damage to cellular macromolecules such as proteins, lipids and DNA, resulting in detrimental effects on cells.

In vitro studies with different sized $(15,30,45 \mathrm{~nm})$ cerium oxide nanoparticles indicated that they exert their toxicity through oxidative stress, which in turn brings about Nrf2-mediated induction of heme oxygenase-1 (HO-1) [63]. Furthermore, silver nanoparticles (AgNPs) of different sizes (4.7 and $42 \mathrm{~nm}$ ) showed the induction of ROS, glutathione depletion, as well as a slight inhibition of superoxide dismutase [64]. Studies with gold nanoparticles (AuNPs) of sizes ranging from 5 to $250 \mathrm{~nm}$ have also revealed that smaller diameter nanoparticles with larger surface area produce higher amounts of ROS, thus establishing an inverse relationship between these two parameters [65]. Both in vitro and in vivo studies with silica nanoparticles indicated that single dose exposure to these nanoparticles leads to ROS induction, consequently activating pro-inflammatory responses [66]. ROS generation, decreased mitochondrial membrane potential, increased levels of lipid peroxide and decreased enzymatic activities of antioxidants were shown to be induced by single-walled carbon nanotubes [67]. Additionally, multi-walled carbon nanotubes also exhibited a dose-dependent induction of ROS [68]. 
Toxicity of nanoparticles is attributed to oxidative stress, followed by DNA damage and apoptosis. Nanoparticles can cause a wide variety of DNA damage, ranging from chromosomal fragmentation, DNA strand breakages and the induction of gene mutations [69-72]. AuNPs (20 nm size) at $1 \mathrm{nM}$ concentration have been shown to exhibit DNA damage in the form of 8-hydroxydoxyguanosine $(8 \mathrm{OHdG})$ adducts formation in embryonic lung fibroblasts with a decreased expression of DNA repair and the cell cycle checkpoint genes MAD2, cyclin B1 and cyclin B2 [73]. Various studies have also confirmed the occurrence of DNA fragmentation and formation of oxidation-induced DNA adducts on exposure to metal oxide nanoparticles [74-76]. In response to this DNA damage, the cells either initiate DNA repair mechanisms or invoke cell cycle arrest and apoptosis. One of the major effector molecules activated in response to DNA damage is p53. It plays a central role in DNA repair and cell cycle arrest, thereby preventing mutagenic events favouring the process of carcinogenesis [77]. Cadmium-telluride quantum dots were found to significantly increase p53 levels and upregulate the p53-downstream effectors Bax, Puma and Noxa in human breast carcinoma cells [78]. Altered expression of DNA damage responsive genes has also been observed in response to nanoparticle exposure. Cultured human embryonic lung fibroblasts exposed to AuNPS showed the down-regulation of DNA repair genes BRCA1, Hus1, ATLD/HNGS1 and AT-V1/AT-V2 [73]. If the extent of DNA damage goes beyond the scope of repair by the DNA repair mechanisms of the body, the cells initiate a programmed cell death. Apoptosis is a highly complex and tightly regulated pathway involving several signaling molecules. Metal oxide nanoparticles including $\mathrm{TiO}_{2}, \mathrm{ZnO}, \mathrm{Fe}_{3} \mathrm{O}_{4}, \mathrm{Al}_{2} \mathrm{O}_{3}$, and $\mathrm{CrO}_{3}$ of particle sizes ranging from 30 to $45 \mathrm{~nm}$ were found to induce apoptosis [79]. In vivo studies with the fruit fly Drosophila models showed that AgNP induces heat shock stress, oxidative stress, DNA damage and apoptosis, thereby mediating developmental and reproductive toxicity [80]. However, the exact cascade of signaling molecules mediating apoptosis in nanoparticle-induced toxicity is poorly studied [81], and thus attempts to better understand this mechanism may prove useful in reducing the toxicological side effects.

\subsection{Inflammation-Mediated Nanotoxicity}

Inflammation is a defence mechanism of the body that involves several immune regulatory molecules, following the infiltration of phagocytic cells. Several studies with single and multi-walled carbon nanotubes and fullerene derivatives have shown the induction of inflammation in varied cell types, including alveolar and bronchial epithelial cells, epidermal keratinocytes and cultured monocyte-macrophage cells [82-85]. More recently, a study was carried out to provide a mechanistic explanation for immune and inflammatory responses observed upon exposure to carbon nanoparticles. The computational model suggested that the carbon nanotubes and $\mathrm{C}_{60}$ fullerenes may be recognized as pathogens by the Toll-like receptors, triggering innate immune responses of the body and secretion of inflammatory protein mediators such as interleukins and chemokines [86]. Furthermore, activation of the complement cascade on exposure to liposomes and other lipid-based nanoparticles leads to hypersensitivity reactions and anaphylaxis [87-89]. However, the exact mechanism of how these complement proteins mediate nanotoxicity has not yet been elucidated [90]. Nanoparticle immunogenicity has also been attributed to their property of acting as adjuvants, thereby improving the antigenicity of conjugated weak antigens [91,92]. The ability of nanoparticles to serve as adjuvants is dependent on 
their size and surface charge, and dictates the type of cytokines that would be released [93]. Importantly, inflammation has been shown to directly cause toxicity and promote cell death through the induction of toxic by-products of inflammation such as ROS and complement proteins, as well as via receptor-induced apoptosis/necrosis [94]. These cascades have not been well explored in the context of nanoparticle-induced cytotoxicity, and investigations in this direction are required to fully identify and recognize the signaling networks mediating inflammation-driven cell death.

Interestingly, oxidative stress also results in the release of pro-inflammatory mediators through the principal cascades such as the NF- $\kappa \mathrm{B}$ (Nuclear Factor- $\kappa \mathrm{B}$ ), mitogen-activated protein kinase (MAPK) and phosphoinositide 3-kinase (PI3-K) pathways [95,96], suggesting that oxidative stress is linked to inflammation reciprocally [81]. In the absence of a stimulus, NF- $\kappa \mathrm{B}$ is sequestered in the cytoplasm by the Inhibitor of $\kappa \mathrm{B}(\mathrm{I} \kappa \mathrm{B})$ family of inhibitors. However, in the event of oxidative stress, the $\mathrm{I} \kappa \mathrm{B}$ undergoes degradation, thus freeing NF- $\kappa \mathrm{B}$ which then translocates into the nucleus to regulate the transcription of its target genes [97]. In support of this, the $\mathrm{OH}, \mathrm{HOCl}$, and ${ }^{1} \mathrm{O}_{2}$ reactive species are known to induce the nuclear translocation and activation of NF- $\mathrm{KB}$ [98]. Both in vitro and in vivo studies showed that nanoparticle-induced lung injury and pulmonary fibrosis lead to the ROS-mediated activation of NF- $\kappa B$ and production of pro-inflammatory mediators such as TNF- $\alpha$, IL- 8 , IL-2 and IL-6 [99,100]. Several metal oxide nanoparticles including zinc, cadmium, silica, and iron have also been shown to exert their toxicity via the production of inflammatory cytokines induced by NF-кB [101-104]. Furthermore, both single-walled and multi-walled carbon nanotubes were also shown to promote inflammatory responses in mice with the production of TNF- $\alpha$ and Monocyte Chemoattractant Protein-1 (MCP-1) [105].

The MAPK pathway regulates a diverse range of cellular responses, including cell proliferation, differentiation, mitosis, cell survival and apoptosis. They are a family of serine/threonine protein kinases that include growth factor-regulated extracellular signal-related kinases (ERK) and the stress-activated MAPK, c-Jun NH2-terminal kinases (JNK) and p38 MAPK. The ERKs are mainly associated with cell proliferation and differentiation, whereas the JNKs and p38 MAPKs are known to regulate responses to cellular stresses [106]. IL-8 production via the p38 MAPK and/or ERK pathway was shown to mediate toxicity in human bronchial epithelial cell line upon treatment with titanium dioxide nanoparticles [107]. In vivo nanotoxicity studies with the model organism C. elegans to assess the effects of AgNPs (size ranging from 20 to $30 \mathrm{~nm}$ ), showed that the toxicity was mediated by increased ROS formation, followed by the increased expression of PMK-1 p38 MAPK and hypoxia-inducible factor (HIF-1) [108]. Moreover, the toxicity of silica nanoparticles which hinders their application as drug delivery systems has been attributed to the activation of JNK, p53 and NF- $\mathrm{B}$ pathways and an elevated expression of pro-inflammatory factors IL-6, IL-8 and MCP-1 [109]. Besides, single-walled carbon nanotubes $(0.8-2 \mathrm{~nm})$ were also shown to cause potential adverse cellular responses in mesothelial cells via the activation of signaling molecules, including ARP, AP-1, NF- $\mathrm{B}$, p38 and Akt, in a dose-dependent manner [110]. On the other hand, the PI3-K/Akt/mTOR pathway is one of the principal signaling cascades regulating cell cycle, thus making it critical for cell survival and growth. PI3-K signaling was found to cause an overexpression of Cox-2, iNOS and pro-inflammatory cytokines (IL-6, IFN- $\gamma$, TNF- $\alpha$, IL-17 and regulatory cytokine IL-10) in macrophages upon exposure to zinc oxide nanoparticles [111]. Furthermore, silica nanoparticles (average diameter of 
$62.1 \pm 7.2 \mathrm{~nm}$ ) were shown to induce inflammatory responses and activate autophagy via the $\mathrm{PI} 3-\mathrm{K} / \mathrm{Akt} / \mathrm{mTOR}$ pathway [112].

\section{Possible Strategies to Circumvent Nanotoxicity}

Oxidative stress results from imbalances in the redox state of the cell. The redox state is disturbed by ROS production in response to nanoparticle exposure and/or nanoparticle-induced inflammation cascade. Many in vitro and in vivo studies have recognized the central role of oxidative stress in mediating nanotoxicity and therefore, the approach of preventing oxidative stress is an ideal strategy in circumventing it.

One possible way to prevent oxidative stress-mediated nanotoxicity is the introduction of ascorbic acid upon nanoparticle exposure. Ascorbic acid, also known as vitamin $\mathrm{C}$, is an antioxidant capable of scavenging free radicals [113]. By introducing ascorbic acid into AgNP-treated acute myeloid leukemia cells there is a complete decrease in ROS production in the cells. Concomitantly, ascorbic acid also led to a decrease in AgNP-induced mitochondria damage, apoptosis and DNA damage, reducing the toxic effects induced by AgNPs [114]. Similar mitigation of ROS generation and glutathione depletion were also observed when ascorbic acid was added to human lung epithelial (A549) cells treated with nickel ferrite nanoparticles (26 nm in diameter) [115]. An in vivo Drosophila melanogaster study has also shown a decrease in nanotoxicity when ascorbic acid was supplemented in the diet of Drosophila exposed to AgNPs [116]. In vivo studies with rats have further revealed that acute oxidative stress and inflammation induced by $\mathrm{ZnO}$ nanoparticles (of particle size $21 \mathrm{~nm}$ ) were alleviated when $1 \%$ aqueous ascorbic acid was given as drinking water [117]. Hence, the administration of ascorbic acid after nanomaterial exposure is a feasible strategy to overcome nanotoxicity, both in vitro and in vitro.

Quercetin, a naturally occurring flavonoid in many plants and food, is an anti-oxidant having free radical scavenging ability. Quercetin has been found to reduce $\mathrm{Fe}_{2} \mathrm{O}_{3}$ nanoparticles-induced oxidative injury and inflammation by increasing Bad phosphorylation and Nrf2 translocation through PI3-K/Akt dependent pathways [118]. In vivo studies have also revealed that $\mathrm{TiO}_{2} \mathrm{NPs}$ induced liver and kidney oxidative stress can be circumvented by treatment with quercetin [119].

Surface modification of nanoparticles can also be carried out to decrease nanotoxicity. An example would be the encapsulation of ascorbic acid with poly (L-glutamic acid)-capped silver nanoparticles (AgNpPGA) within a poly (lactide-co-glycolide) (PLGA) polymeric matrix (PLGA/AgNpPGA/ascorbic acid particles). A reduction in ROS generation was observed in HepG2 cells treated with the PLGA/AgNpPGA/ascorbic acid particles as compared to control cells, suggesting that nanoparticles encapsulated with ascorbic acid can reduce oxidative stress in cells, possibly decreasing the nanotoxic effects of nanoparticles [120]. Copper nanoparticles coated with polysaccharides such as chitosan have also shown to decrease in vitro toxicity and ROS generation, although the modification increased inflammatory responses when administered via the lung [121]. Furthermore, $\mathrm{Fe}_{2} \mathrm{O}_{3}$ nanoparticles coated with chitosan resulted in a decrease in cellular damage and moderated ROS production, thereby, reducing the cytotoxic effects of the nanoparticles [122]. Polymer coatings such as polyethylene glycol (PEG) on superparamagnetic iron oxide nanoparticles (SPIONs) have also effectively reduced nanoparticle cytotoxicity by reducing ROS formation. The PEG coating blocks 
ROS interaction with the $\mathrm{Fe}_{2} \mathrm{O}_{3}$ nanoparticles (of diameter 5 and $30 \mathrm{~nm}$ ), thus preventing formation of hydroxyl radicals and allowing the cell's antioxidant defense mechanisms to neutralize ROS before they become toxic [123].

The NF- $\kappa B$, MAPK and PI3-K pathways facilitate nanoparticle-induced inflammation, and release of several pro-inflammatory cytokines and chemokines including TNF- $\alpha$, IL- 6 and IL-8, leading to cytotoxicity and cell death. With the intention of combating inflammation, the Jun/AP-1 pathway components have been modulated providing new avenues for therapeutic interventions [124]. Hence, targeting these signaling molecules also holds promise as an effective tool to evade/circumvent the inflammation-mediated toxicity, thereby allowing for the development of nanoparticle-based applications in the field of medicine.

\section{Conclusions}

Nanoparticles hold great potential in the field of nanomedicine due to their favourable physicochemical properties. However, nanotoxicity has become a growing concern of nanotechnology. Numerous in vitro and in vivo studies have consistently demonstrated that nanoparticles induce ROS production, causing an imbalance in the redox state and subsequently leading to an oxidative stress in the cell, as illustrated in Figure 1. Therefore, strategies targeting the oxidative stress hold great potential in further developing nanoparticle-based tools for medical applications by eradicating nanotoxicity.

- Anti-oxidant induction (Ascorbic acid, Quercetin) ○ Surface modifications of nanoparticles

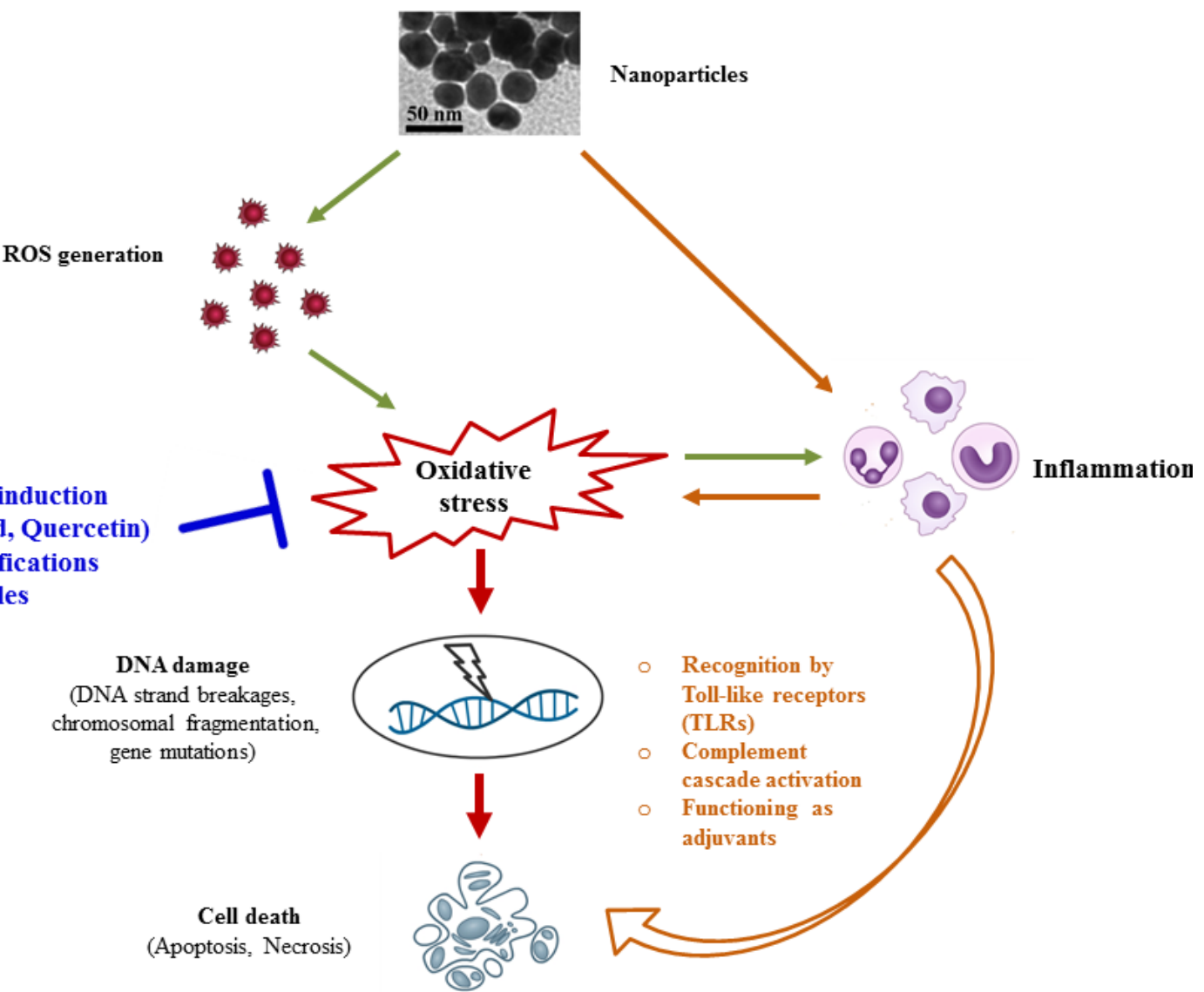

Figure 1. Overview of the signaling cascades mediating nanotoxicity, and possible strategies to circumvent the toxicity. 


\section{Acknowledgments}

The authors would like to thank Song Lin Bay from the Department of Anatomy, National University of Singapore for technical assistance.

\section{Author Contributions}

P.K., C.O. and G-H.B. contributed to reviewing literatures and writing of the manuscript. B-H.B. facilitated reviewing and proofreading of the manuscript.

\section{Conflicts of Interest}

The authors declare no conflict of interest.

\section{References}

1. Roco, M.C. National Nanotechnology Initiative-Past, Present, Future. In Handbook on Nanoscience, Engineering and Technology, 2nd ed.; Taylor and Francis Group: Oxford, UK, 2007; pp. 3.1-3.26.

2. Lanone, S.; Boczkowski, J. Biomedical applications and potential health risks of nanomaterials: Molecular mechanisms. Curr. Mol. Med. 2006, 6, 651-663.

3. National Science and Technology Council. National Nanotechnology Initiative Strategic Plan; Executive Office of the President of the United States: Washington, DC, USA, 2004.

4. European Science Foundation. Nanomedicine: An. ESF-European Medical Research Councils (EMRC) forward Look Report; European Science Foundation: Strasbourg Cedex, France, 2005.

5. Agnihotri, S.A.; Mallikarjuna, N.N.; Aminabhavi, T.M. Recent advances on chitosan-based micro- and nanoparticles in drug delivery. J. Control. Release 2004, 100, 5-28.

6. Lee, L.J. Polymer nano-engineering for biomedical applications. Ann.Biomed. Eng. 2006, 34, 75-88.

7. Fornaguera, C.; Dols-Perez, A.; Caldero, G.; Garcia-Celma, M.J.; Camarasa, J.; Solans, C. PLGA nanoparticles prepared by nano-emulsion templating using low-energy methods as efficient nanocarriers for drug delivery across the blood-brain barrier. J. Control. Release 2015, $211,134-143$.

8. Cherian, A.K.; Rana, A.C.; Jain, S.K. Self-assembled carbohydrate-stabilized ceramic nanoparticles for the parenteral delivery of insulin. Drug Dev. Ind. Pharm. 2000, 26, 459-463.

9. Chen, Y.; Chen, H.; Shi, J. Drug delivery/imaging multifunctionality of mesoporous silica-based composite nanostructures. Expert Opin. Drug Deliv. 2014, 11, 917-930.

10. Mahmoudi, M.; Sant, S.; Wang, B.; Laurent, S.; Sen, T. Superparamagnetic iron oxide nanoparticles (spions): Development, surface modification and applications in chemotherapy. Adv. Drug Deliv. Rev. 2011, 63, 24-46.

11. Gupta, A.K.; Gupta, M. Synthesis and surface engineering of iron oxide nanoparticles for biomedical applications. Biomaterials 2005, 26, 3995-4021.

12. Peng, M.; Li, H.; Luo, Z.; Kong, J.; Wan, Y.; Zheng, L.; Zhang, Q.; Niu, H.; Vermorken, A.; van de Ven, W.; et al. Dextran-coated superparamagnetic nanoparticles as potential cancer drug carriers in vitro. Nanoscale 2015, 7, 11155-11162. 
13. Hirsch, L.R.; Gobin, A.M.; Lowery, A.R.; Tam, F.; Drezek, R.A.; Halas, N.J.; West, J.L. Metal nanoshells. Ann. Biomed. Eng. 2006, 34, 15-22.

14. Zhang, H.; Wang, C.; Chen, B.; Wang, X. Daunorubicin-TiO 2 nanocomposites as a "smart" ph-responsive drug delivery system. Int. J. Nanomed. 2012, 7, 235-242.

15. Franci, G.; Falanga, A.; Galdiero, S.; Palomba, L.; Rai, M.; Morelli, G.; Galdiero, M. Silver nanoparticles as potential antibacterial agents. Molecules 2015, 20, 8856-8874.

16. Bosi, S.; Da Ros, T.; Spalluto, G.; Prato, M. Fullerene derivatives: An attractive tool for biological applications. Eur. J. Med. Chem. 2003, 38, 913-923.

17. Pagona, G.; Tagmatarchis, N. Carbon nanotubes: Materials for medicinal chemistry and biotechnological applications. Curr. Med. Chem. 2006, 13, 1789-1798.

18. Geho, D.H.; Lahar, N.; Ferrari, M.; Petricoin, E.F.; Liotta, L.A. Opportunities for nanotechnology-based innovation in tissue proteomics. Biomed. Microdevices 2004, 6, 231-239.

19. Wang, D.; Li, Y.; Lin, Z.; Qiu, B.; Guo, L. Surface-enhanced electrochemiluminescence of $\mathrm{Ru} @ \mathrm{SiO}_{2}$ for ultrasensitive detection of carcinoembryonic antigen. Anal. Chem. 2015, 87, 5966-5972.

20. Wang, Y.; Ju, Z.; Cao, B.; Gao, X.; Zhu, Y.; Qiu, P.; Xu, H.; Pan, P.; Bao, H.; Wang, L.; et al. Ultrasensitive rapid detection of human serum antibody biomarkers by biomarker-capturing viral nanofibers. ACS Nano 2015, 9, 4475-4483.

21. Bhalgat, M.K.; Haugland, R.P.; Pollack, J.S.; Swan, S.; Haugland, R.P. Green- and red-fluorescent nanospheres for the detection of cell surface receptors by flow cytometry. J. Immunol. Methods 1998, 219, 57-68.

22. Nam, J.M.; Thaxton, C.S.; Mirkin, C.A. Nanoparticle-based bio-bar codes for the ultrasensitive detection of proteins. Science 2003, 301, 1884-1886.

23. Medina, C.; Santos-Martinez, M.J.; Radomski, A.; Corrigan, O.I.; Radomski, M.W. Nanoparticles: Pharmacological and toxicological significance. Br. J. Pharmacol. 2007, 150, $552-558$.

24. Sheng, Y.; Liao, L.D.; Thakor, N.V.; Tan, M.C. Nanoparticles for molecular imaging. J. Biomed. Nanotechnol. 2014, 10, 2641-2676.

25. Wickline, S.A.; Lanza, G.M. Nanotechnology for molecular imaging and targeted therapy. Circulation 2003, 107, 1092-1095.

26. Lanza, G.M.; Wickline, S.A. Targeted ultrasonic contrast agents for molecular imaging and therapy. Curr. Probl. Cardiol. 2003, 28, 625-653.

27. Lanza, G.M.; Abendschein, D.R.; Yu, X.; Winter, P.M.; Karukstis, K.K.; Scott, M.J.; Fuhrhop, R.W.; Scherrer, D.E.; Wickline, S.A. Molecular imaging and targeted drug delivery with a novel, ligand-directed paramagnetic nanoparticle technology. Acad. Radiol. 2002, 9, S330-S331.

28. Flacke, S.; Fischer, S.; Scott, M.J.; Fuhrhop, R.J.; Allen, J.S.; McLean, M.; Winter, P.; Sicard, G.A.; Gaffney, P.J.; Wickline, S.A.; et al. Novel mri contrast agent for molecular imaging of fibrin: Implications for detecting vulnerable plaques. Circulation 2001, 104, 1280-1285.

29. Wang, X.F.; Jin, P.P.; Tong, Z.; Zhao, Y.P.; Ding, Q.L.; Wang, D.B.; Zhao, G.M.; Jing, D.; Wang, H.L.; Ge, H.L. MR molecular imaging of thrombus: Development and application of a Gd-based novel contrast agent targeting to P-selectin. Clin. Appl. Thromb. Hemost. 2010, 16, 177-183. 
30. Aime, S.; Castelli, D.D.; Crich, S.G.; Gianolio, E.; Terreno, E. Pushing the sensitivity envelope of lanthanide-based magnetic resonance imaging (MRI) contrast agents for molecular imaging applications. Acc. Chem. Res. 2009, 42, 822-831.

31. Sapra, P.; Tyagi, P.; Allen, T.M. Ligand-targeted liposomes for cancer treatment. Curr. Drug Deliv. 2005, 2, 369-381.

32. Abu Lila, A.S.; Ishida, T.; Kiwada, H. Targeting anticancer drugs to tumor vasculature using cationic liposomes. Pharm. Res. 2010, 27, 1171-1183.

33. Fonseca, C.; Simoes, S.; Gaspar, R. Paclitaxel-loaded PLGA nanoparticles: Preparation, physicochemical characterization and in vitro anti-tumoral activity. J. Control. Release 2002, 83, 273-286.

34. Bhadra, D.; Bhadra, S.; Jain, S.; Jain, N.K. A pegylated dendritic nanoparticulate carrier of fluorouracil. Int. J. Pharm. 2003, 257, 111-124.

35. Gnad-Vogt, S.U.; Hofheinz, R.D.; Saussele, S.; Kreil, S.; Willer, A.; Willeke, F.; Pilz, L.; Hehlmann, R.; Hochhaus, A. Pegylated liposomal doxorubicin and mitomycin $\mathrm{C}$ in combination with infusional 5-fluorouracil and sodium folinic acid in the treatment of advanced gastric cancer: Results of a phase II trial. Anti-Cancer Drugs 2005, 16, 435-440.

36. Donaldson, K.; Stone, V.; Tran, C.L.; Kreyling, W.; Borm, P.J. Nanotoxicology. Occup. Environ. Med. 2004, 61, 727-728.

37. Oberdörster, G.; Oberdörster, E.; Oberdörster, J. Nanotoxicology: An emerging discipline evolving from studies of ultrafine particles. Environ. Health Perspect. 2005, 113, 823-839.

38. Grabinski, C.; Hussain, S.; Lafdi, K.; Braydich-Stolle, L.; Schlager, J. Effect of particle dimension on biocompatibility of carbon nanomaterials. Carbon 2007, 45, 2828-2835.

39. Li, X.; Liu, W.; Sun, L.; Aifantis, K.E.; Yu, B.; Fan, Y.; Feng, Q.; Cui, F.; Watari, F. Effects of physicochemical properties of nanomaterials on their toxicity. J. Biomed. Mater. Res. A 2015, 103, 2499-2507.

40. Lam, C.W.; James, J.T.; McCluskey, R.; Hunter, R.L. Pulmonary toxicity of single-wall carbon nanotubes in mice 7 and 90 days after intratracheal instillation. Toxicol. Sci. 2004, 77, 126-134.

41. Morimoto, Y.; Horie, M.; Kobayashi, N.; Shinohara, N.; Shimada, M. Inhalation toxicity assessment of carbon-based nanoparticles. Acc. Chem. Res. 2013, 46, 770-781.

42. Singh, D.; Singh, S.; Sahu, J.; Srivastava, S.; Singh, M.R. Ceramic nanoparticles: Recompense, cellular uptake and toxicity concerns. Artif. Cells Nanomed. Biotechnol. 2014, doi:10.3109/21691401.2014.955106.

43. Radomski, A.; Jurasz, P.; Alonso-Escolano, D.; Drews, M.; Morandi, M.; Malinski, T.; Radomski, M.W. Nanoparticle-induced platelet aggregation and vascular thrombosis. Br. J. Pharm. 2005, 146, 882-893.

44. Cui, D.; Tian, F.; Ozkan, C.S.; Wang, M.; Gao, H. Effect of single wall carbon nanotubes on human HEK293 cells. Toxicol. Lett. 2005, 155, 73-85.

45. Alazzam, A.; Mfoumou, E.; Stiharu, I.; Kassab, A.; Darnel, A.; Yasmeen, A.; Sivakumar, N.; Bhat, R.; Al Moustafa, A.E. Identification of deregulated genes by single wall carbon-nanotubes in human normal bronchial epithelial cells. Nanomedicine 2010, 6, 563-569.

46. Younes, N.R.; Amara, S.; Mrad, I.; Ben-Slama, I.; Jeljeli, M.; Omri, K.; El Ghoul, J.; El Mir, L.; Rhouma, K.B.; Abdelmelek, H.; et al. Subacute toxicity of titanium dioxide $\left(\mathrm{TiO}_{2}\right)$ nanoparticles 
in male rats: Emotional behavior and pathophysiological examination. Environ. Sci. Pollut. Res. Int. 2015, 22, 8728-8737.

47. Shrivastava, R.; Raza, S.; Yadav, A.; Kushwaha, P.; Flora, S.J. Effects of sub-acute exposure to $\mathrm{TiO}_{2}, \mathrm{ZnO}$ and $\mathrm{Al}_{2} \mathrm{O}_{3}$ nanoparticles on oxidative stress and histological changes in mouse liver and brain. Drug Chem. Toxicol. 2014, 37, 336-347.

48. Liu, Y.; Xu, Z.; Li, X. Cytotoxicity of titanium dioxide nanoparticles in rat neuroglia cells. Brain Inj. 2013, 27, 934-939.

49. Li, T.; Shi, T.; Li, X.; Zeng, S.; Yin, L.; Pu, Y. Effects of nano-MnO ${ }_{2}$ on dopaminergic neurons and the spatial learning capability of rats. Int. J. Environ. Res. Public Health 2014, 11, 7918-7930.

50. Lademann, J.; Weigmann, H.; Rickmeyer, C.; Barthelmes, H.; Schaefer, H.; Mueller, G.; Sterry, W. Penetration of titanium dioxide microparticles in a sunscreen formulation into the horny layer and the follicular orifice. Skin Pharmacol. Appl. Skin Physiol. 1999, 12, 247-256.

51. Trop, M.; Novak, M.; Rodl, S.; Hellbom, B.; Kroell, W.; Goessler, W. Silver-coated dressing acticoat caused raised liver enzymes and argyria-like symptoms in burn patient. J. Trauma 2006, 60, 648-652.

52. Nemmar, A.; Yuvaraju, P.; Beegam, S.; Yasin, J.; Dhaheri, R.A.; Fahim, M.A.; Ali, B.H. In vitro platelet aggregation and oxidative stress caused by amorphous silica nanoparticles. Int. J. Physiol. Pathophysiol. Pharmacol. 2015, 7, 27-33.

53. Xu, Y.; Wang, N.; Yu, Y.; Li, Y.; Li, Y.B.; Yu, Y.B.; Zhou, X.Q.; Sun, Z.W. Exposure to silica nanoparticles causes reversible damage of the spermatogenic process in mice. PLOS ONE 2014, 9, e101572.

54. Laurent, S.; Saei, A.A.; Behzadi, S.; Panahifar, A.; Mahmoudi, M. Superparamagnetic iron oxide nanoparticles for delivery of therapeutic agents: Opportunities and challenges. Expert Opin. Drug Deliv. 2014, 11, 1449-1470.

55. Alkilany, A.M.; Murphy, C.J. Toxicity and cellular uptake of gold nanoparticles: What we have learned so far? J. Nanopart. Res. 2010, 12, 2313-2333.

56. Huo, L.; Chen, R.; Zhao, L.; Shi, X.; Bai, R.; Long, D.; Chen, F.; Zhao, Y.; Chang, Y.Z.; Chen, C. Silver nanoparticles activate endoplasmic reticulum stress signaling pathway in cell and mouse models: The role in toxicity evaluation. Biomaterials 2015, 61, 307-315.

57. Lin, W.; Stayton, I.; Huang, Y.-W.; Zhou, X.-D.; Ma, Y. Cytotoxicity and cell membrane depolarization induced by aluminum oxide nanoparticles in human lung epithelial cells A549. Toxicol. Environ. Chem. 2008, 90, 983-996.

58. Fahmy, B.; Cormier, S.A. Copper oxide nanoparticles induce oxidative stress and cytotoxicity in airway epithelial cells. Toxicol. In vitro 2009, 23, 1365-1371.

59. Manke, A.; Wang, L.; Rojanasakul, Y. Mechanisms of nanoparticle-induced oxidative stress and toxicity. Biomed Res. Int. 2013, 2013, 15.

60. Sarkar, A.; Ghosh, M.; Sil, P.C. Nanotoxicity: Oxidative stress mediated toxicity of metal and metal oxide nanoparticles. J. Nanosci. Nanotechnol. 2014, 14, 730-743.

61. Knaapen, A.M.; Borm, P.J.; Albrecht, C.; Schins, R.P. Inhaled particles and lung cancer. Part A: Mechanisms. Int. J. Cancer 2004, 109, 799-809. 
62. Risom, L.; Møller, P.; Loft, S. Oxidative stress-induced DNA damage by particulate air pollution. Mutat. Res. 2005, 592, 119-137.

63. Eom, H.J.; Choi, J. Oxidative stress of ceo2 nanoparticles via p38-Nrf-2 signaling pathway in human bronchial epithelial cell, Beas-2B. Toxicol. Lett. 2009, 187, 77-83.

64. Avalos, A.; Haza, A.I.; Mateo, D.; Morales, P. Cytotoxicity and ros production of manufactured silver nanoparticles of different sizes in hepatoma and leukemia cells. J. Appl. Toxicol. 2014, 34, 413-423.

65. Misawa, M.; Takahashi, J. Generation of reactive oxygen species induced by gold nanoparticles under X-ray and UV irradiations. Nanomedicine 2011, 7, 604-614.

66. Park, E.-J.; Park, K. Oxidative stress and pro-inflammatory responses induced by silica nanoparticles in vitro and in vitro. Toxicol. Lett. 2009, 184, 18-25.

67. Wang, J.; Sun, P.; Bao, Y.; Liu, J.; An, L. Cytotoxicity of single-walled carbon nanotubes on PC12 cells. Toxicol. In vitro 2011, 25, 242-250.

68. Zhornik, E.V.; Baranova, L.A.; Strukova, A.M.; Loiko, E.N.; Volotovskii, I.D. ROS induction and structural modification in human lymphocyte membrane under the influence of carbon nanotubes. Biofizika 2012, 57, 446-453.

69. Singh, N.; Manshian, B.; Jenkins, G.J.S.; Griffiths, S.M.; Williams, P.M.; Maffeis, T.G.G.; Wright, C.J.; Doak, S.H. Nanogenotoxicology: The DNA damaging potential of engineered nanomaterials. Biomaterials 2009, 30, 3891-3914.

70. Alarifi, S.; Ali, D.; Alkahtani, S. Nanoalumina induces apoptosis by impairing antioxidant enzyme systems in human hepatocarcinoma cells. Int. J. Nanomed. 2015, 10, 3751-3760.

71. Al Gurabi, M.A.; Ali, D.; Alkahtani, S.; Alarifi, S. In vitro DNA damaging and apoptotic potential of silver nanoparticles in swiss albino mice. Onco Targets Ther. 2015, 8, 295-302.

72. Sliwinska, A.; Kwiatkowski, D.; Czarny, P.; Milczarek, J.; Toma, M.; Korycinska, A.; Szemraj, J.; Sliwinski, T. Genotoxicity and cytotoxicity of $\mathrm{ZnO}$ and $\mathrm{Al}_{2} \mathrm{O}_{3}$ nanoparticles. Toxicol. Mech. Methods 2015, 25, 176-183.

73. Li, J.J.; Zou, L.; Hartono, D.; Ong, C.N.; Bay, B.H.; Lanry Yung, L.Y. Gold nanoparticles induce oxidative damage in lung fibroblasts in vitro. Adv. Mater. 2008, 20, 138-142.

74. Bhattacharya, K.; Davoren, M.; Boertz, J.; Schins, R.; Hoffmann, E.; Dopp, E. Titanium dioxide nanoparticles induce oxidative stress and DNA-adduct formation but not DNA-breakage in human lung cells. Part. Fibre Toxicol. 2009, 6, doi:10.1186/1743-8977-6-17.

75. Lin, W.; Xu, Y.; Huang, C.-C.; Ma, Y.; Shannon, K.B.; Chen, D.-R.; Huang, Y.-W. Toxicity of nano-and micro-sized $\mathrm{ZnO}$ particles in human lung epithelial cells. J. Nanopart. Res. 2009, 11, 25-39.

76. Karlsson, H.L.; Cronholm, P.; Gustafsson, J.; Moller, L. Copper oxide nanoparticles are highly toxic: A comparison between metal oxide nanoparticles and carbon nanotubes. Chem. Res. Toxicol. 2008, 21, 1726-1732.

77. Lane, D.P. Cancer. P53, guardian of the genome. Nature 1992, 358, 15-16.

78. Choi, A.O.; Brown, S.E.; Szyf, M.; Maysinger, D. Quantum dot-induced epigenetic and genotoxic changes in human breast cancer cells. J. Mol. Med. 2008, 86, 291-302.

79. Jeng, H.A.; Swanson, J. Toxicity of metal oxide nanoparticles in mammalian cells. J. Environ. Sci. Health A 2006, 41, 2699-2711. 
80. Ahamed, M.; Posgai, R.; Gorey, T.J.; Nielsen, M.; Hussain, S.M.; Rowe, J.J. Silver nanoparticles induced heat shock protein 70, oxidative stress and apoptosis in Drosophila melanogaster. Toxicol. Appl. Pharmacol. 2010, 242, 263-269.

81. Huang, Y.-W.; Wu, C.-H.; Aronstam, R.S. Toxicity of transition metal oxide nanoparticles: Recent insights from in vitro studies. Materials 2010, 3, 4842-4859.

82. Baktur, R.; Patel, H.; Kwon, S. Effect of exposure conditions on SWCNT-induced inflammatory response in human alveolar epithelial cells. Toxicol. In vitro 2011, 25, 1153-1160.

83. Crouzier, D.; Follot, S.; Gentilhomme, E.; Flahaut, E.; Arnaud, R.; Dabouis, V.; Castellarin, C.; Debouzy, J.C. Carbon nanotubes induce inflammation but decrease the production of reactive oxygen species in lung. Toxicology 2010, 272, 39-45.

84. Rouse, J.G.; Yang, J.; Barron, A.R.; Monteiro-Riviere, N.A. Fullerene-based amino acid nanoparticle interactions with human epidermal keratinocytes. Toxicol. In vitro 2006, 20, 1313-1320.

85. Qu, C.; Wang, L.; He, J.; Tan, J.; Liu, W.; Zhang, S.; Zhang, C.; Wang, Z.; Jiao, S.; Liu, S.; et al. Carbon nanotubes provoke inflammation by inducing the pro-inflammatory genes IL-1 $\beta$ and IL-6. Gene 2012, 493, 9-12.

86. Turabekova, M.; Rasulev, B.; Theodore, M.; Jackman, J.; Leszczynska, D.; Leszczynski, J. Immunotoxicity of nanoparticles: A computational study suggests that CNTs and C60 fullerenes might be recognized as pathogens by toll-like receptors. Nanoscale 2014, 6, 3488-3495.

87. Dobrovolskaia, M.A.; Aggarwal, P.; Hall, J.B.; McNeil, S.E. Preclinical studies to understand nanoparticle interaction with the immune system and its potential effects on nanoparticle biodistribution. Mol. Pharm. 2008, 5, 487-495.

88. Chanan-Khan, A.; Szebeni, J.; Savay, S.; Liebes, L.; Rafique, N.M.; Alving, C.R.; Muggia, F.M. Complement activation following first exposure to pegylated liposomal doxorubicin (Doxil): Possible role in hypersensitivity reactions. Ann. Oncol. 2003, 14, 1430-1437.

89. Szebeni, J.; Alving, C.R.; Rosivall, L.; Bunger, R.; Baranyi, L.; Bedocs, P.; Toth, M.; Barenholz, Y. Animal models of complement-mediated hypersensitivity reactions to liposomes and other lipid-based nanoparticles. J. Liposome Res. 2007, 17, 107-117.

90. Zolnik, B.S.; González-Fernández, Á.; Sadrieh, N.; Dobrovolskaia, M.A. Nanoparticles and the immune system. Endocrinology 2010, 151, 458-465.

91. Reddy, S.T.; van der Vlies, A.J.; Simeoni, E.; Angeli, V.; Randolph, G.J.; O’Neil, C.P.; Lee, L.K.; Swartz, M.A.; Hubbell, J.A. Exploiting lymphatic transport and complement activation in nanoparticle vaccines. Nat. Biotechnol. 2007, 25, 1159-1164.

92. Fifis, T.; Gamvrellis, A.; Crimeen-Irwin, B.; Pietersz, G.A.; Li, J.; Mottram, P.L.; McKenzie, I.F.; Plebanski, M. Size-dependent immunogenicity: Therapeutic and protective properties of nano-vaccines against tumors. J. Immunol. 2004, 173, 3148-3154.

93. Mottram, P.L.; Leong, D.; Crimeen-Irwin, B.; Gloster, S.; Xiang, S.D.; Meanger, J.; Ghildyal, R.; Vardaxis, N.; Plebanski, M. Type 1 and 2 immunity following vaccination is influenced by nanoparticle size: Formulation of a model vaccine for respiratory syncytial virus. Mol. Pharm. 2007, 4, 73-84.

94. Wallach, D.; Kang, T.-B.; Kovalenko, A. Concepts of tissue injury and cell death in inflammation: A historical perspective. Nat. Rev. Immunol. 2014, 14, 51-59. 
95. Poljak-Blaži, M.; Jaganjac, M.; Žarković, N. Cell Oxidative Stress: Risk of Metal Nanoparticles; CRC Press Taylor: London, UK; New York, NY, USA, 2010.

96. Li, J.J.E.; Muralikrishnan, S.; Ng, C.-T.; Yung, L.-Y.L.; Bay, B.-H. Nanoparticle-induced pulmonary toxicity. Exp.Biol. Med. 2010, 235, 1025-1033.

97. Allen, R.; Tresini, M. Oxidative stress and gene regulation. Free Radic. Biol. Med. 2000, 28, 463-499.

98. Ye, J.; Zhang, X.; Young, H.A.; Mao, Y.; Shi, X. Chromium(VI)-induced nuclear factor- $\kappa B$ activation in intact cells via free radical reactions. Carcinogenesis 1995, 16, 2401-2405.

99. Byrne, J.D.; Baugh, J.A. The significance of nanoparticles in particle-induced pulmonary fibrosis. McGill J. Med. 2008, 11, 43-50.

100. Monteiller, C.; Tran, L.; MacNee, W.; Faux, S.; Jones, A.; Miller, B.; Donaldson, K. The pro-inflammatory effects of low-toxicity low-solubility particles, nanoparticles and fine particles, on epithelial cells in vitro: The role of surface area. Occup. Environ. Med. 2007, 64, 609-615.

101. Hubbard, A.K.; Timblin, C.R.; Shukla, A.; Rincón, M.; Mossman, B.T. Activation of NF-kB-dependent gene expression by silica in lungs of luciferase reporter mice. Am. J. Physiol.-Lung Cell. Mol. Physiol. 2002, 282, L968-L975.

102. Pujalté, I.; Passagne, I.; Brouillaud, B.; Tréguer, M.; Durand, E.; Ohayon-Courtès, C.; L'Azou, B. Cytotoxicity and oxidative stress induced by different metallic nanoparticles on human kidney cells. Part. Fibre Toxicol. 2011, 8, 1-16.

103. Wu, W.; Samet, J.M.; Peden, D.B.; Bromberg, P.A. Phosphorylation of p65 is required for zinc oxide nanoparticle-induced interleukin 8 expression in human bronchial epithelial cells. Environ. Health Perspect. 2010, 118, 982-987.

104. Kahn, E.; Baarine, M.; Pelloux, S.; Riedinger, J.-M.; Frouin, F.; Tourneur, Y.; Lizard, G. Iron nanoparticles increase 7-ketocholesterol-induced cell death, inflammation, and oxidation on murine cardiac hl1-nb cells. Int. J. Nanomed. 2010, 5, 185-195.

105. Nygaard, U.C.; Hansen, J.S.; Samuelsen, M.; Alberg, T.; Marioara, C.D.; Løvik, M. Single-walled and multi-walled carbon nanotubes promote allergic immune responses in mice. Toxicol. Sci. 2009, 109, 113-123.

106. Torres, M.; Forman, H.J. Redox signaling and the map kinase pathways. BioFactors 2003, 17, 287-296.

107. Park, E.-J.; Yi, J.; Chung, K.-H.; Ryu, D.-Y.; Choi, J.; Park, K. Oxidative stress and apoptosis induced by titanium dioxide nanoparticles in cultured BEAS-2B cells. Toxicol. Lett. 2008, 180, $222-229$.

108. Lim, D.; Roh, J.-Y.; Eom, H.-J.; Choi, J.-Y.; Hyun, J.; Choi, J. Oxidative stress-related PMK-1 p38 mapk activation as a mechanism for toxicity of silver nanoparticles to reproduction in the nematode Caenorhabditis elegans. Environ. Toxicol. Chem. 2012, 31, 585-592.

109. Liu, X.; Sun, J. Endothelial cells dysfunction induced by silica nanoparticles through oxidative stress via jnk/p53 and NF-кB pathways. Biomaterials 2010, 31, 8198-8209.

110. Pacurari, M.; Yin, X.J.; Zhao, J.; Ding, M.; Leonard, S.S.; Schwegler-Berry, D.; Ducatman, B.S.; Sbarra, D.; Hoover, M.D.; Castranova, V. Raw single-wall carbon nanotubes induce oxidative stress and activate MAPKs, AP-1, NF- $\kappa \mathrm{B}$, and Akt in normal and malignant human mesothelial cells. Environ. Health Perspect. 2008, 116, 1211-1217. 
111. Roy, R.; Parashar, V.; Chauhan, L.K.S.; Shanker, R.; Das, M.; Tripathi, A.; Dwivedi, P.D. Mechanism of uptake of $\mathrm{ZnO}$ nanoparticles and inflammatory responses in macrophages require PI3K mediated mapks signaling. Toxicol. In vitro 2014, 28, 457-467.

112. Duan, J.; Yu, Y.; Yu, Y.; Li, Y.; Wang, J.; Geng, W.; Jiang, L.; Li, Q.; Zhou, X.; Sun, Z. Silica nanoparticles induce autophagy and endothelial dysfunction via the PI3K/Akt/mTOR signaling pathway. Int J. Nanomed. 2014, 9, 5131-5141.

113. Niki, E. Action of ascorbic acid as a scavenger of active and stable oxygen radicals. Am. J. Clin. Nutr. 1991, 54, 1119s-1124s.

114. Guo, D.; Zhu, L.; Huang, Z.; Zhou, H.; Ge, Y.; Ma, W.; Wu, J.; Zhang, X.; Zhou, X.; Zhang, Y.; et al. Anti-leukemia activity of PVP-coated silver nanoparticles via generation of reactive oxygen species and release of silver ions. Biomaterials 2013, 34, 7884-7894.

115. Ahamed, M.; Akhtar, M.J.; Siddiqui, M.A.; Ahmad, J.; Musarrat, J.; Al-Khedhairy, A.A.; AlSalhi, M.S.; Alrokayan, S.A. Oxidative stress mediated apoptosis induced by nickel ferrite nanoparticles in cultured a549 cells. Toxicology 2011, 283, 101-108.

116. Posgai, R.; Cipolla-McCulloch, C.B.; Murphy, K.R.; Hussain, S.M.; Rowe, J.J.; Nielsen, M.G. Differential toxicity of silver and titanium dioxide nanoparticles on drosophila melanogaster development, reproductive effort, and viability: Size, coatings and antioxidants matter. Chemosphere 2011, 85, 34-42.

117. Fukui, H.; Iwahashi, H.; Endoh, S.; Nishio, K.; Yoshida, Y.; Hagihara, Y.; Horie, M. Ascorbic acid attenuates acute pulmonary oxidative stress and inflammation caused by zinc oxide nanoparticles. J. Occup. Health 2015, 57, 118-125.

118. Sarkar, A.; Sil, P.C. Iron oxide nanoparticles mediated cytotoxicity via PI3K/Akt pathway: Role of quercetin. Food Chem. Toxicol. 2014, 71, 106-115.

119. Gonzalez-Esquivel, A.E.; Charles-Nino, C.L.; Pacheco-Moises, F.P.; Ortiz, G.G.; Jaramillo-Juarez, F.; Rincon-Sanchez, A.R. Beneficial effects of quercetin on oxidative stress in liver and kidney induced by titanium dioxide $\left(\mathrm{TiO}_{2}\right)$ nanoparticles in rats. Toxicol. Mech. Methods 2015, 25, 1-10.

120. Stevanovic, M.; Bracko, I.; Milenkovic, M.; Filipovic, N.; Nunic, J.; Filipic, M.; Uskokovic, D.P. Multifunctional PLGA particles containing poly(L-glutamic acid)-capped silver nanoparticles and ascorbic acid with simultaneous antioxidative and prolonged antimicrobial activity. Acta Biomater. 2014, 10, 151-162.

121. Worthington, K.L.; Adamcakova-Dodd, A.; Wongrakpanich, A.; Mudunkotuwa, I.A.; Mapuskar, K.A.; Joshi, V.B.; Allan Guymon, C.; Spitz, D.R.; Grassian, V.H.; Thorne, P.S.; et al. Chitosan coating of copper nanoparticles reduces in vitro toxicity and increases inflammation in the lung. Nanotechnology 2013, 24, doi: 10.1088/0957-4484/24/39/395101.

122. Shukla, S.; Jadaun, A.; Arora, V.; Sinha, R.K.; Biyani, N.; Jain, V.K. In vitro toxicity assessment of chitosan oligosaccharide coated iron oxide nanoparticles. Toxicol. Rep. 2015, 2, 27-39.

123. Yu, M.; Huang, S.; Yu, K.J.; Clyne, A.M. Dextran and polymer polyethylene glycol (PEG) coating reduce both 5 and $30 \mathrm{~nm}$ iron oxide nanoparticle cytotoxicity in 2D and 3D cell culture. Int. J. Mol. Sci. 2012, 13, 5554-5570. 
124. Schonthaler, H.B.; Guinea-Viniegra, J.; Wagner, E.F. Targeting inflammation by modulating the Jun/AP-1 pathway. Ann. Rheum. Dis. 2011, 70, i109-i112.

(C) 2015 by the authors; licensee MDPI, Basel, Switzerland. This article is an open access article distributed under the terms and conditions of the Creative Commons Attribution license (http://creativecommons.org/licenses/by/4.0/). 